\title{
THE INFLUENCE OF SCUBA DIVERS’ PERSONALITY, EXPERIENCE, AND DEMOGRAPHIC PROFILE ON THEIR UNDERWATER BEHAVIOR
}

\author{
GHAZALI MUSA, WONG TONG SENG, \\ THINARANJENEY THIRUMOORTHI, and MASOUD ABESSI
}

Faculty of Business and Accountancy, University of Malaya, Kuala Lumpur, Malaysia

\begin{abstract}
Scuba diving activity is known to cause detrimental impact on the marine environment and its sustainability. This study explores the influence of divers' personality, experience, and demographic profile on their underwater behavior. Data were collected using convenience sampling among divers in Malaysia. A total of 302 questionnaires were returned and analyzed. The results show that divers are generally responsible underwater. Scuba diving experience parameters of duration of involvement, number of dives, self-rating experience, and diving frequency influence underwater behavior. Divers with high neuroticism are more likely to be irresponsible, while high agreeableness personality factor is related to more responsible behavior underwater. Based on the results the authors provide some managerial recommendations in order to promote responsible scuba diving activities.
\end{abstract}

Key words: Scuba divers; Personality; Experience; Underwater behavior

\section{Introduction}

Divers have a crucial role to play in marine environmental conservation as their diving activities can result in detrimental impact to the fragile ecology. How seriously the ecology will be affected, however, depends to a large extent on the divers' behavior underwater. Their behavior underwater could be a function of experience (Thapa, Graefe, \& Meyer, 2006), demographic characteristics (Cottrell, 2003; Diamantopoulos, Schlegelmilch, Sinkovics, \& Bohlen, 2003; Luna, Valle Pérez, \& Sánchez-Lizaso, 2009; Rouphael \& Inglis, 2001; Sirakaya, 1997), and perhaps personality (Fernan- dez \& Castro, 2003; Ford, Miller, \& Moss, 2001; Furnhman, 1990; Phares, 1991). Among other factors that influence the behavior of divers underwater are the use of cameras (Barker \& Roberts, 2004; Rouphael \& Inglis, 2002), predive briefing (Medio, Ormond, \& Pearson, 1997), active leader intervention (Barker \& Roberts, 2004), and buoyancy control (Harriott, Davis, \& Banks, 1997).

A positive association between experience and underwater behavior was recorded in the study by Thapa et al. (2006), which found that as specialization in scuba diving increases, so does environmentally responsible behavior. Experienced divers are less likely to have uncontrollable contacts on 
coral reefs (Davis, Harriot, MacNamara, Robert, \& Austin, 1995) and experienced recreationists have lower impact practices (Dyck, Schneider, Thomas, \& Virden, 2003).

Studies also found the influences of demographic variables on behavior. Male divers are more responsible than female divers according to Rouphael and Inglis (2001), Luna et al. (2009), and Sirakaya (1997). However, the reverse is true in the studies of Uyarra and Cote (2007) and Worachananant et al. (2008). Surprisingly, Cottrell (2003) found as age, education, and income increase, the environmental concern decreases. According to Diamantopoulos et al. (2003), the responsible behavior of recycling is more frequently practiced by older and higher educated people.

One aspect that has not yet been examined is how the personality traits influence the behavior of divers underwater. This is the unique contribution of this study. Evidence from the literature on psychology unanimously demonstrates that people's personality will greatly influence their behavior (Furnhman, 1990; Phares, 1991). For example, anxiety personality (which is an element of neuroticism) has a depressive effect on recreational activities (Fernandez \& Castro, 2003; Ford et al., 2001).

There are five main objectives of this study:

1. To explore the demographic profile of scuba divers.

2. To identify scuba divers experience.

3. To examine the personality of scuba divers.

4. To examine the behavior of scuba divers underwater.

5. To explore the influences of demographic profile, divers' experience and divers' personality on their behavior underwater.

The article begins with the review of literature related to scuba diving, scuba diving underwater behavior, personality, and scuba diving experience. This is followed by the description of research methodology. Results and discussions will be presented before drawing up a final conclusion.

\section{Literature Review}

\section{Scuba Diving Research}

Scuba diving is a marine ecotourism activity (Cater \& Cater, 2001; Garrod \& Wilson, 2003).
The activity is subclassified as adventure by Ewert (1989) for its associated element of danger, and nature-based activity (Blamey 2001) for having the core element of activity in nature. Today, scuba diving is one of the fastest rising sports and in the expanding market for special interest tourism with up to 1 million people become certified divers annually (Bennet, 2003; Dignan, 1990).

With the continuous growth of tourism activities, the concern about marine environment has increased (Thapa et al., 2006). Currently, Mastny (2001) stated that about $60 \%$ of the world's reefs are under threat, while $27 \%$ have already disappeared (Global Coral Reef Monitoring Network, 2000). Major tourist-dependent communities specializing in dive tourism expect extensive damage to their reefs due to heavy concentration of divers at certain sites (Hawkins \& Roberts, 1994).

Various studies on scuba diving have been conducted (Barker \& Roberts, 2004; Bennet, 2003; Davis, 1993; Harriott et al., 1997; MacCarthy, O'Neill, \& Williams, 2006; Medio et al., 1997; Musa, 2002; O'Neill, Williams, MacCarthy, \& Groves, 2000; Rouphael \& Hanafy, 2007; Rouphael \& Inglish, 2002; Stolk et al., 2007; Tabata, 1992; Thapa et al., 2006; Uy, Caindec, Perez, \& Dy, 2005; Zakai \& Chadwick-Furman, 2002). Among those who studied the negative environmental impact of scuba diving activities are Davis (1993), Rouphael and Hanafy (2007), Bennet (2003), Rouphael and Inglish (2002), Thapa et al., (2006), and Dearden, Bennet, and Rollins (2007). All of them agreed that divers' behavior play a crucial role in maintaining the sustainability of the marine environment and the scuba diving industry.

Davis (1993) warned that there may be significant and irreversible biological damage to the coral reefs as a result of too much diving activity. His view was supported by Bennet (2003), who stated that even though the impact on the marine environment of an individual diver may be minor, the cumulative impact of many divers can be significant. Bennet (2003) proposed that divers should be educated on appropriate scuba diving behaviors.

Rouphael and Hanafy (2007) reviewed management frameworks used in marine protected areas to limit the impact of scuba divers on coral assemblages, including the carrying capacity approach and limits of acceptable change. The 
authors concluded that scuba diving can cause ecological changes in coral assemblages and commented that existing management frameworks used to limit the impact of diving have major shortcomings. They commented that the emphasis on limiting the number may not be that effective and proposed that management actions should also include behavior modification.

\section{Underwater Behavior}

According to International Coral Reef Action Network (ICRAN) Mesoamerican Reef Alliance (2006) divers must obey all applicable local and national laws and regulations, including interactions with marine life, maintaining an awareness of fins, equipment, and cameras, adjusting buoyancy, and securing equipment from contacting corals or stirring up sediments. Divers are not allowed to touch or contact corals or other reef-dwelling organisms. Spearing, chasing, harassing, or riding any marine life such as turtles, manatees, and whale sharks, as well as feeding them, should be strictly prohibited. Marine ecotourists are not allowed to collect shells or corals as souvenirs and stand or rest on coral reefs. They are expected to dive safely, both for their health and for the protection of marine environment. Divers are required to update diving skills such as buoyancy control, finning, and positioning (Marine Ecotourism for the Atlantic Area [META], 2001). Harriott et al. (1997) observed that most of the damage is caused by divers with poor buoyancy control and finning techniques.

Barker and Roberts (2004) observed 353 divers in St. Lucia and noted contacts by divers with the reef commonly occurred during the first $10 \mathrm{~min}$ utes of the dive, when divers were adjusting their equipment and becoming familiar with the underwater environment. Most contacts with the reef $(81.4 \%)$ were caused by fin kicks. The majority of contacts $(81.2 \%)$ appeared unintentional and caused by poor swimming technique, incorrect weighting, and ignorance. Camera users were far more likely to contact the reef and to cause coral breakage than noncamera users (Barker \& Roberts, 2004; Rouphael \& Inglis, 2002). Divers with cameras are 3.5 times more likely to have contact with corals and 100 times more likely to break the coral compared with divers without camera (Barker \& Roberts, 2004).
Medio et al. (1997) examined the effects of briefing on the rates of damage to corals by scuba divers in Ras Mohammed National Park, Egypt. Following the environmental briefing, there was a change both in the proportions of voluntary and involuntary contacts and in the type of substrata contacted by divers underwater. Those who received the briefing did consciously try to avoid unnecessary contacts with living reef elements. However, Barker and Roberts (2004) cautioned that the inclusion of one sentence reference to not touching the reef does not reduce divers' contact. They proposed the need for active intervention by a dive leader as an effective means to reduce damaging contacts with corals. Rouphael and Inglis (2001) stated that precautionary briefings are likely to be more effective if the stress is put on cumulative impacts that accrue from the relatively minor effects of many individual divers, rather than by simply focusing on elements of individual behavior.

In Israel's Eilat, Zakai and Chadwick-Furman (2002) recommended several changes to be made to reduce current levels of coral damage caused by divers. Among them are limiting the total number of dives per reef site per year, requiring that all dives be led by guides, transferring training courses and introductory dives from fragile reefs to more robust sandy areas, diverting recreational diver pressure away from overloaded natural coral reefs to artificial reef areas, and improving the environmental education of divers in certification training courses, by incorporating mandatory sessions on how to behave underwater around coral reefs. There is no study so far examine the influence of scuba divers personality on their underwater behavior.

\section{The Role of Personality}

Phares (1991) defined personality as a pattern of characteristic thoughts, feelings, and behaviors that distinguishes one person from another that persists over time and situation. The dispositional personality perspective depicts personality as made up by physiologically based traits, which guide behavior. Traits can be described as tendencies to behave and react in a specific way.

Fraj and Martinez (2006) found that personality is a multifaceted concept, which is positively re- 
lated to ecological behavior. Each individual tends to display the characteristics of either side of this dimension, being either more withdrawn or more outgoing. However, it is rare to find a person who is totally representative of the traits that form any one pole of the dimension.

Over the 5 decades of personality research, there is common agreement that there are five core dimensions that constitute our personality (Heinstrom, 2005; Howard \& Howard, 1998). According to John and Srivastava (1999), these dimensions capture a broad level of abstraction and provide an integrative descriptive model for personality research. The five core personality dimensions (traits) are neuroticism, extraversion, openness to experience, agreeableness, and conscientiousness. The dimensions have been used in many researchers in their studies. Among them are Fernandez and Castro (2003), Heinstrom (2005), Howard and Howard (1998), Vermetten, Lodewijks, and Vermunt (2001), Kent (1998), Braam, Mooi, Jonker, Van Tillburg, and Deeg (2008), Fraj and Martinez (2006), Marshall, Wortman, Vickers, Kusulas, and Hervig (1994), and Chapman, Lyness, and Duberstein (2007).

Persons with high levels of "neuroticism" are reactive to stimuli in their environment. They easily become unstable, worried, temperamental, and sad (Howard \& Howard, 1998). Neuroticism does not necessarily refer to any psychiatric defect. McCrae and John (1992) referred to this dimension as negative affectivity or emotional instability. According to Ford et al. (2001), anxiety has a negative influence on recreation activities. This is also observed by Fernandez and Castro (2003) who found that neuroticism has a depressing effect on recreation activities.

Extroverts tend to be more physically and verbally active whereas introverts are independent, reserved, steady, and like being alone (Howard \& Howard, 1998). The openness to experience trait is related to intellectual behaviors, receptive to new ideas, and interested in culture (Heinstrom, 2005). People with low openness to experience are conventional, conservative, and prefer familiarity (Howard \& Howard, 1998).

The agreeableness scale is associated with altruism, nurturance, caring, and supportive, versus hostility, indifference, self-centeredness, spiteful- ness, and jealousy (Howard \& Howard, 1998). Agreeableness relates to propensities to enact various prosocial behaviors and more constructive communication (Jensen-Campbell, Gleason, \& Adam, 2003). According to Letzring (2008), agreeable people are responsible, have good social skills, are psychologically well adjusted, express warmth, and seem to enjoy interaction. Conscientiousness is a measure of goal-directed behavior and control over impulses (Howard \& Howard, 1998). The more conscientious a person is the more competent, dutiful, orderly, responsible, and thoughtful he/she is (Costa \& McCrae, 1992). Other than personality, which may influence the behavior of divers, the role of their scuba diving experience has already been established.

\section{The Role of Scuba Diving Experience}

Thapa et al. (2006) explored the relationship between recreational specialization and marinebased environmental behaviors among scuba divers in St. Petersburg/Sarasota, Florida Gulf coast (USA). The authors identified a positive association between the level of specialization and marine-based environmental behaviors, finding that as specialization in scuba diving increased, environmentally responsible behaviors also increased. The skill of buoyancy control is crucial for divers in order to avoid contact with coral (Thapa et al., 2006). They also concluded that higher confidence levels and the ability to adapt to different diving situations, such as strong currents, poor visibility, or different diving environments can reduce contact with marine environments.

According to expertise theories (Etelapelto, 1998), experience acquired in authentic work practices is a prerequisite for competence construction and for the development of expertise. The level of skill and experience has been related with greater environmental awareness and more emphasis among divers on the preservation of natural environment (Thapa et al., 2006). Mowen, Williams, and Graefe (1997) suggested that highly skilled and experienced recreationists are more aware of sitespecific environmental issues than with general or broad environmental issues. The recent study of mountaineers revealed that highly experienced climbers are more concerned about the impact of 
their activities on the environment and they favor low-impact practices (Dyck et al., 2003).

Scuba diving experience resulted in significant changes in perceptions of diving impacts (Dearden et al., 2007). Divers who witnessed impacts were more likely than other divers to agree that diving has a negative impact on fish and coral, and causes harm through improper garbage handling and crowding. Divers who witnessed the impacts were significantly more likely to indicate interest in a reef monitoring project following their dive trip than divers who do not see impacts (Dearden et al., 2007). Davis et al. (1995) found that more experienced divers (those with more than 100 logged dives) made significantly less uncontrollable contacts than less experienced divers.

\section{The Influence of Demographic Variables on Scuba Diving Behavior}

In two separate studies in the Malaysian islands of Sipadan (Musa, 2002) and Layang-Layang (Musa, Latifah, \& Lee, 2006) divers were found to be predominantly male, young, and educated. Cottrell and Meisel (2003) noted that none of the diver background variables (age, education, skill level, number of dives logged, years of diving experience) were predictors of personal responsibility. However, Rouphael and Inglis (2001) found that male and female divers appear to display distinctly different underwater behaviors. Women were generally more cautious when diving close to the substratum, and more likely to use their hands, rather than their fins to support themselves. This is in line with Luna et al. (2009) and Sirakaya, (1997). According to Luna et al. (2009), men caused higher contact frequency with coral for flapping compared with women. They proposed that the contact could be reduced by giving more explicit predive warnings to male divers and underwater photographers about the extra care they should take during their dive. Sirakaya (1997) found that female tour operators are more inclined to comply with the guidelines than their male counterparts.

Deferring to the above claims, Uyarra and Cote (2007) and Worachananant et al. (2008) discovered that female divers inflict more negative impacts on the marine environment than male divers.
Uyarra and Cote (2007) observed that female divers show a higher propensity for damaging behavior than men when near seahorses and frogfish. Even though female divers logged similar number of dives, they appeared to be relatively less experienced in avoiding the contact with substratum. Worachananant et al. (2008), who had a similar finding, argued that the differences in physical capacity and the ability to handle the heavy scuba equipment and currents may have contributed to this situation rather than the care or concern toward the marine environment.

As stated in the introduction, Cottrell (2003) found that age, income, and education are significant but yet negative predictors of environmental concern. This means that as income, age, and education increase, environmental concern decreases. Diamantopoulos et al. (2003) claimed that older and higher educated people are more likely to recycle than the ordinary citizens.

\section{Methodology}

Data collection was carried out using the selfadministered questionnaire. A total of 302 divers from the various major diving centers and diving resorts in Klang Valley, Penang, Kelantan, Terengganu, Pahang, Sabah, and Sarawak responded to the questionnaire. The convenience sampling was employed and authors relied on the voluntary responses of dive members of those organizations. Questionnaires were also distributed using snowballing sample through friends and e-mail.

There were four sections of the questionnaire. These were experience, personality, underwater behavior, and demographic profile. Divers' experience was measured using seven exploratory parameters adapted from Thapa et al. (2006), Musa (2002), and Musa et al. (2006). However, the focus was given on the measurement of cognitive and behavioral aspects of the experience. As mentioned earlier by Etelapelto (1998), expertise theories advocate that experience acquired in authentic work practices is a prerequisite for competence construction and for the development of expertise. Experience was measured by duration of involvement, total dives, diving certification, self-rating experience, dive environment, countries that divers had dived before, and frequency of diving. 
There are numerous personality tests available such as Thematic Apperception Test, Minnesota Multiphasic Personality Test, Myers-Briggs Type Indicator, Keirsey Temperament Sorter, 16 Personality Factors, Eysenck Personality Questionnaire, and Swedish University Scale of Personality. In this study, divers' personality was tested by the NEO Five-Factor Inventory (NEO FFI), which is a short version of the Revised NEO Personality Inventory (NEO PI-R). The NEO FFI is a wellestablished personality test based on the fivefactor model of personality. This model posits that the basic traits dimensions in human personality are neuroticism, extraversion, openness to experience, agreeableness, and conscientiousness (Costa $\&$ McCrae, 1992). Each of the five personality dimensions was measured by four items, making a total of 20 items.

Previous literature has stated that there are two methods for measuring scuba divers' behavior. These are by observation (Barker \& Roberts, 2004; Medio, 1997; Uyarra \& Cote 2007) and selfreporting behavior (Arney, 2004; Eccles et al., 2006; Thapa et al., 2006). The limitation of using observation is time and resources. One-to-one observation is time consuming, expensive, and not without shortcomings. Most observations are carried out during the first 10 minutes of normally an hour dive (Barker \& Roberts, 2004; Rouphael \& Inglis, 2002). Poor visibility and the possibility of divers feeling that they were being observed alter considerably the accuracy of the findings. Even though most of the contacts occurred during first 10 minutes of the dives (Barker \& Roberts 2004), the majority of them were accidental. This study only focused on the behavior that divers were aware of happening during the dive. Thus, the self-reporting method was employed. Arney (2004) and Thapa et al. (2006) noted the advantage of this type of enquiry as it allows the measurement of several irresponsible behaviors using different response formats (Arney, 2004).

A total of 19 scuba diving behavior items were included in the study (Harriott et al., 1997; ICRAN, 2006; META, 2001). Thirteen marine-based environmental behavior items were adapted from Thapa (2000) and Todd (2000). The remaining seven items were taken from the environmental code of conduct published by a conservation orga- nization (Coral Reef Alliance and The International Ecotourism Society; in Thapa et al., 2006). Following scale purification nine items were deleted. Among them were "participate in community clean up," "read books and magazines about marine environment," "brought diving sausage," and "used protective gloves." The remaining 10 items were used for the further analysis in the study. The divers' demographic profiles examined were gender, age, education background, ethnicity, and level of income.

\section{Results}

The results will be presented according to orders of the stated objectives in the introduction section.

\section{Demographic Profile}

Table 1 presents the demographic profile of the divers. Males made up the majority of respondents $(60.9 \%)$ while females constituted $39.1 \%$. Divers between 30 and 39 years old constituted $44.4 \%$ of

Table 1

Demographic Profile

\begin{tabular}{lr}
\hline Demographics & Frequency $(\%)$ \\
\hline Gender & \\
Male & $184(60.9 \%)$ \\
Female & $118(39.1 \%)$ \\
Age & $72(23.8 \%)$ \\
$18-29$ & $134(44.4 \%)$ \\
$30-39$ & $84(27.8 \%)$ \\
$40-49$ & $12(4.0 \%)$ \\
$50-59$ & \\
Ethnicity & $92(30.5 \%)$ \\
Malay & $184(60.9 \%)$ \\
Chinese & $11(3.6 \%)$ \\
Indian & $15(5.0 \%)$ \\
Others & \\
Education background & $9(3.0 \%)$ \\
Secondary school \& lower & $28(9.3 \%)$ \\
High school & $75(24.8 \%)$ \\
Diploma & $168(55.6 \%)$ \\
Graduate & $22(7.3 \%)$ \\
Postgraduate & \\
Annual income & $27(8.9 \%)$ \\
Less than RM10,000 & $28(9.3 \%)$ \\
RM10,000-24,999 & $75(24.8 \%)$ \\
RM25,000-49,999 & $80(26.5 \%)$ \\
RM50,000-74,999 & $49(16.2 \%)$ \\
RM75,000-99,999 & $43(14.2 \%)$ \\
RM100,000 and above &
\end{tabular}


the respondents. This is followed by $27.8 \%$ of those between 40 and 49 years and $23.8 \%$ between 18 and 29 years old. The majority of divers $(60.9 \%)$ were Chinese in ethnicity. Malays made up $30.5 \%$ and Indians $3.6 \%$. With regard to educational background, the majority of the respondents were graduates $(55.6 \%)$. The second highest educational achievement was diploma (24.8\%), followed by high school $(9.3 \%)$, and postgraduates (7.3\%). The majority of divers earned between RM50,000 and RM74,999 (26.5\%), followed by $24.8 \%$ who earned between RM25,000 and RM49,999. Some divers (14.2\%) earned more than RM100,000.

\section{Divers' Experience}

Table 2 presents scuba divers' experience. A total of 120 respondents $(39.7 \%)$ have been involved in scuba diving activity for more than 10 years. Those involved 1-4 years and 5-9 years represented $32.5 \%$ and $21.9 \%$, respectively. In terms of total diving trips, $41.7 \%$ of the respondents have dived more than 201 times and $20.5 \%$ dived between 51 and 100 times. Four levels of scuba diving certification were measured and the majority of them were at Advanced Certification (43.4\%). These were followed by $20.5 \%$ Open Water Certification, $18.5 \%$ Instructor Certification, and $17.5 \%$ Dive-master Certification.

In terms of self-rating experience, the majority of divers $(47.0 \%)$ rated themselves at Intermediate Level. This was followed by $32.1 \%$ who rated themselves as Expert and 20.9\% Beginners. All divers $(100 \%)$ have dived in the ocean. Divers who have dived wreck, cave, and freshwater lake were $68.2 \%, 40.4 \%$, and $27.8 \%$, respectively. Divers who have dived in 1-3 countries constituted $59.6 \%$. This was followed by $34.4 \%$ who have dived in 4-6 countries and $6.3 \%$ in $10-12$ countries. In terms of frequency of diving, $69.2 \%$ of respondents dived several times per year, $24.5 \%$ dived once in a year, and $2.6 \%$ dived once in 2 years.

Male divers rated themselves significantly more experienced $($ mean $=22.55, \mathrm{SD}=6.69)$ than female divers $($ mean $=19.96, \mathrm{SD}=6.40 ; t(257)=$ $3.34, p=0.001)$. Divers' experience showed significant difference among ethnic groups $[F(3,298)=$
Table 2

Divers' Experience

\begin{tabular}{lrr}
\hline Experience & Frequency $(\%)$ \\
\hline Involvement in SCUBA diving activity & & \\
Less than 1 year & 18 & $(6.0 \%)$ \\
1-4 years & 98 & $(32.5 \%)$ \\
5-9 years & 66 & $(21.9 \%)$ \\
10 years or more & 120 & $(39.7 \%)$ \\
Total diving trips & & \\
Less than 50 & 53 & $(17.5 \%)$ \\
$51-100$ & 62 & $(20.5 \%)$ \\
101-150 & 28 & $(9.3 \%)$ \\
151-200 & 33 & $(10.9 \%)$ \\
201 and above & 126 & $(41.7 \%)$ \\
Level of scuba diving certification & & \\
Open water & 62 & $(20.5 \%)$ \\
Advanced & 131 & $(43.4 \%)$ \\
Dive master & 53 & $(17.5 \%)$ \\
Instructor & 56 & $(18.5 \%)$ \\
Divers level & & \\
Beginner 63 (20.9\%) & 142 & $(47.0 \%)$ \\
Intermediate & 97 & $(32.1 \%)$ \\
Expert & & \\
Places of diving & 302 & $(100.0 \%)$ \\
Ocean & 84 & $(27.8 \%)$ \\
Fresh water lake & 206 & $(68.2 \%)$ \\
Wreck & 122 & $(40.4 \%)$ \\
Cave & & \\
No. of countries that have been dived & 180 & $(59.6 \%)$ \\
1-3 countries & 101 & $(33.4 \%)$ \\
4-6 countries & 19 & $(6.3 \%)$ \\
7-9 countries & 2 & $(0.7 \%)$ \\
10-12 countries & 3 & \\
Frequency of dive in a year & 3 & $(1.0 \%)$ \\
Less than once in 5 years & 8 & $(2.6 \%)$ \\
Once in 3 years & 8 & $(2.6 \%)$ \\
Once in 2 years & 74 & $(24.5 \%)$ \\
Once in a year & 209 & $(69.2 \%)$ \\
Several times per year & & \\
& & \\
& & \\
& &
\end{tabular}

$13.26, p=0.000]$. Others ethnicity reported significantly higher in scuba diving experience (mean = 26.2, $\mathrm{SD}=7.01)$. This is followed by Chinese $($ mean $=22.84, \mathrm{SD}=6.32)$, Indian $($ mean $=20.00$, $\mathrm{SD}=5.39$ ), and Malays (mean $=18.37, \mathrm{SD}=6.28)$.

Older divers reported higher experience compared with the younger divers $[F(3,298)=26.46$, $p=0.000]$. The most experienced divers were among age group of 50-57 years old (mean = 27.25, SD =4.24). This is followed by the age group of 40-49 years old $($ mean $=24.75, \mathrm{SD}=$ $5.37), 30-39$ years old $($ mean $=21.53, \mathrm{SD}=6.70)$, and $18-19$ years old $($ mean $=16.86, \mathrm{SD}=2.83)$. Divers with graduate level of education reported a significantly higher experience $($ mean $=22.23, \mathrm{SD}=$ 
6.64) compared with divers who achieved diploma in education $($ mean $=19.47, \mathrm{SD}=6.67)[F(4,297)=$ 2.68, $p=0.032]$.

\section{Diver's Personality}

Referring to Table 3, divers possessed the highest personality scores of agreeableness (mean $=$ 4.06 ) and conscientiousness (mean $=4.02)$. Personality scores of neuroticism $($ mean $=2.20)$ and extroversion $($ mean $=3.63$ ) were rated lower. Cronbach alpha values of personality factors showed strong internal consistency: extraversion (0.852), neuroticism $(0.810)$, openness to experience $(0.810)$, agreeableness (0.864), and conscientiousness (0.842).

An independent samples $t$-test was conducted to examine the difference of personality dimen-

Table 3

Mean Score of Personality Dimensions

\begin{tabular}{|c|c|}
\hline Personality Dimension & Mean (SD) \\
\hline \multicolumn{2}{|l|}{ Extroversion } \\
\hline Talkative & $3.27(0.96)$ \\
\hline Energy & $3.71(0.76)$ \\
\hline Enthusiasm & $3.69(0.69)$ \\
\hline Sociable & $3.84(0.92)$ \\
\hline Average score for Extroversion & $3.63(0.83)$ \\
\hline Cronbach alpha: 0.852 & \\
\hline \multicolumn{2}{|l|}{ Neuroticism } \\
\hline Depressed & $1.94(0.90)$ \\
\hline Tense & $2.56(1.23)$ \\
\hline Worried & $2.17(1.00)$ \\
\hline Nervous & $2.14(0.89)$ \\
\hline Average score for Neuroticism & $2.20(1.01)$ \\
\hline Cronbach alpha: 0.810 & \\
\hline \multicolumn{2}{|l|}{ Open to experience } \\
\hline New idea & $3.67(0.76)$ \\
\hline Imagination & $3.91(0.92)$ \\
\hline Inventive & $3.52(0.90)$ \\
\hline Reflect idea & $3.89(0.80)$ \\
\hline Average score for Open to Experience & $3.75(0.85)$ \\
\hline Cronbach alpha: 0.810 & \\
\hline \multicolumn{2}{|l|}{ Agreeableness } \\
\hline Helpful & $3.99(0.67)$ \\
\hline Forgiveness & $3.98(0.69)$ \\
\hline Considerate & $4.14(0.64)$ \\
\hline Cooperate & $4.11(0.63)$ \\
\hline Average score for Agreeableness & $4.06(0.66)$ \\
\hline Cronbach alpha: 0.864 & \\
\hline \multicolumn{2}{|l|}{ Conscientiousness } \\
\hline Thorough job & $4.10(0.80)$ \\
\hline Emotionally stable & $4.03(0.66)$ \\
\hline Effective & $4.10(0.74)$ \\
\hline Self-esteem & $3.83(0.77)$ \\
\hline Average score for Conscientiousness & $4.02(0.74)$ \\
\hline Cronbach alpha: 0.842 & \\
\hline
\end{tabular}

sions with gender. Male divers scored significantly higher "extroversion" $[$ mean $=14.84, \mathrm{SD}=$ 2.61) compared with females (mean $=13.99, \mathrm{SD}=$ $2.36[t(300)=2.85, p=0.005]$. They also scored higher for the personality factor of "open to experience" $($ mean $=15.45, \mathrm{SD}=2.85)$ compared to the female $($ mean $=14.26, \mathrm{SD}=2.32)[t(283.30)=$ $3.96, p=0.000]$. On the other hand, female divers scored significantly higher in "neuroticism" (mean = 9.42, $\mathrm{SD}=2.63)$ compared with males (mean = 8.43, SD = 3.53) $[t(293.12)=-2.774, p=0.006]$.

All five personality factors showed significant differences with age. For extroversion dimension older age group of 40-49 years old had higher score $($ mean $=15.27, \mathrm{SD}=2.27)$ compared with the younger age group of 18-29 years old (mean = 13.76, $\mathrm{SD}=2.70) \quad[F(3,298)=4.84, p=0.003]$. Younger divers between 18 and 29 years old, on the other hand, had higher score of neuroticism (mean $=9.72, \mathrm{SD}=3.52$ ) compared with the older age group between 40 and 49 years old (mean = $8.22, \mathrm{SD}=3.12)[F(3,298)=3.39, p=0.018]$.

In terms "openness to experience" dimension, the score was significantly higher with the increasing age $[F(3,298)=9.28, p=0.000]$. Young divers of 18-29 years old scored significantly lower (mean $=15.63, \mathrm{SD}=2.31)$ "agreeableness" dimension compared with older divers of 40-49 years old $($ mean $=16.82, \mathrm{SD}=1.93) \quad[F(3,298)=3.92$, $p=0.009$ ]. Divers between 40 and 49 years old scored the highest in "conscientiousness" dimension $($ mean $=16.68, \mathrm{SD}=2.06)[F(3,298)=4.02$, $p=0.008]$. This dimension scored the lowest among the youngest age group of 18-29 years old (mean $=15.33, \mathrm{SD}=2.63)$ and the older age group of 50-57 years old $($ mean $=15.92, \mathrm{SD}=2.31)$.

In terms of education background, three personality dimensions were significantly different. Divers with a degree had higher personality dimension of "open to experience" (mean $=15.39$, $\mathrm{SD}=2.59)$ compared with divers with only high school education $($ mean $=13.57, \mathrm{SD}=2.74)[F(4$, $297)=4.18, p=0.003$ ]. "Agreeableness" dimension somehow was higher among divers with diploma $($ mean $=15.64, \mathrm{SD}=2.59)$ compared with divers with a degree $($ mean $=15.57, \mathrm{SD}=1.91)$ $[F(4,297)=2.96, p=0.020]$. Conscientiousness dimension was higher with higher educational level $[F(4,297)=4.86, p=0.001]$. 
Neuroticism $[F(3,298)=4.82, p<0.003]$ and conscientiousness $[F(3,298)=4.33, p=0.005]$ dimensions were significantly different in terms of ethnicity. Indian divers scored the highest "neuroticism" dimension (mean $=12.36, \mathrm{SD}=3.64)$ compared with the Malays (mean $=8.55, \mathrm{SD}=2.83$ ) and Chinese $($ mean $=8.74, \mathrm{SD}=3.20)$. Chinese divers scored higher in "conscientiousness" dimension $\quad($ mean $=16.41, \quad \mathrm{SD}=2.17) \quad$ compared with the Malays (mean $=15.43, \mathrm{SD}=2.76$ ).

\section{Diver's Marine-Based Underwater Behavior}

The mean scored for all the irresponsible underwater behavior items was low (range from 1.93 to 1.38) (Table 4). This clearly indicates that the respondents were very responsible. The highest three items of irresponsible underwater behavior scores relate to diving safety: dived too deep (mean $=1.93, \mathrm{SD}=1.13)$, separated from diving buddies $($ mean $=1.77, \mathrm{SD}=1.11)$, and ascended too fast $($ mean $=1.73, \mathrm{SD}=1.05)$. The lowest irresponsible behavior scores relate the disturbances to marine life $($ mean $=1.51)$, hunted marine life for personal consumption $($ mean $=1.39)$, and ridden marine animal (mean $=1.38)$.

Factor analysis was performed in order to identify the underlying constructs of marine-based underwater behavior. Principal axis factoring was carried out, followed by Varimax rotation with Kaiser Normalization. The KMO's value was 0.920 and only one component was derived with

\section{Table 4}

Irresponsible Marine-Based Underwater Behavior

\section{Behavior}

Mean (SD)

\section{Dived too deep}

Separated from my diving buddy

Ascended too fast

Stood or held on to coral for support

Fed aquatic life while underwater

Touched shipwreck, artifact, or coral for closer examination

Touched shipwreck, artifact, or coral to take photo

Disturbed marine life

Hunted marine life for personal consumption

Ridden marine animal

$1=$ never, $2=$ rarely, $3=$ sometimes, $4=$ frequent, $5=$ always. the variance explained at $73.09 \%$. The sole component derived is named as irresponsible underwater behavior. Cronbach's alpha value was 0.958 , which indicates a very strong contribution of all the items for the factor.

\section{The Influences of Demographic Profile, Divers' Experience, and Divers' Personality on Their Behavior Underwater}

One-way ANOVA indicated that only age group $[F(3,298)=4.69, p=0.003]$ and ethnicity $[F(3,298)=6.89, p=0.000]$ of the respondents were significant in influencing irresponsible behavior underwater. Irresponsible behavior scored highest among age group of 19-29 years (mean = 19.63, $\mathrm{SD}=10.19$ ) compared with older age groups. In terms of ethnicity, Indians (mean = 27.28, $\mathrm{SD}=12.82$ ) scored the highest irresponsible behavior compared with other races (Malay, mean $=16.25, \mathrm{SD}=7.89$; Chinese, mean $=15.45$, $\mathrm{SD}=8.97$; other races mean $=17.00, \mathrm{SD}=8.49$ ).

All the seven experience parameters: "year of diving," "total dives," "diving certification," "safe-rating experience," "places of diving," "overseas diving experience," and "frequency of diving in a year" were given scores following which the score of scuba diving experience construct was calculated. The construct score ranged from the lowest of 7 to the highest of 35. Using a statistical technique divers were divided into three groups: low experience, moderate experience, and high experience. Only the low experience and the high experience were used to examine the influence of experience on scuba diving behavior. The low and high experience categories were represented by 59 and 36 respondents, respectively. An independent sample $t$-test was conducted to examine the influence of these two category experiences on underwater behavior. The results showed that the low $($ mean $=17.69, \mathrm{SD}=8.60)$ and high experience $($ mean $=17.64, \mathrm{SD}=13.44)$ divers do not significantly different in their influence on the marine based underwater behavior.

Even though the aggregate form of scuba diving experience did not influence the underwater behavior, some of its individual parameters did. These were duration of involvement, total number of dives, self-rating experience, and frequency of 
diving. With the advancing years of involvement in scuba diving, divers will more likely to be responsible [less than 1 year $($ mean $=24.78, \mathrm{SD}=$ 9.83), $1-4$ years $($ mean $=16.34, \mathrm{SD}=7.68), 5-9$ years $($ mean $=16.52, \mathrm{SD}=11.22)$, and 10 years above $($ mean $=14.67, \quad \mathrm{SD}=7.94)] \quad[F(3,298)=$ $6.944, p=0.000]$. Divers who dived between 101 and 150 dives scored higher irresponsible behavior (mean $=20.64, \mathrm{SD}=13.45)$ compared with those who dived 201 and above times (mean $=14.87$, $\mathrm{SD}=8.39) \quad[F(4,297)=3.000, p=0.019]$. Irresponsible behavior was higher among Beginners (mean $=18.92, \mathrm{SD}=9.89)$ compared with Intermediate $($ mean $=15.42, \mathrm{SD}=7.65)$ and Expert divers $($ mean $=15.64, \mathrm{SD}=10.09)[F(2,299)=3.626$, $p=0.028]$. Divers were most responsible when they dive several times $($ mean $=14.95, \mathrm{SD}=7.93$ ) a year and the least responsible when the dive once in 2 years $($ mean $=22.25, \mathrm{SD}=8.28)[F(4$, 297) $=3.988, p=0.004$ ]

A regression analysis was performed in order to examine the influence of diver's personality on marine based underwater behavior (see Table 5). $R^{2}=0.383$, which implied that $38.3 \%$ of marinebased underwater behavior is explained by personality and experience. Only two of the personality dimensions were significant: neuroticism and agreeableness $[F(6,295)=30.527, p=0.000]$. The strongest predictor in influencing underwater behavior was neuroticism dimension, which scored positive standardized coefficients beta value of 0.598 .

Divers with higher neuroticism possess higher irresponsible marine-based underwater behavior. On the other hand, the agreeableness dimension produced beta value score of -0.220 in influencing underwater behavior. The negative relationship signifies that divers who are higher in agreeableness personality are less likely to be irresponsible underwater. The remaining three dimensions of personality; extraversion, open to experience, and conscientiousness are not significant predictors of marine-based underwater behavior.

\section{Discussion}

This study is an excellent extension to the understanding of pertinent factors that influence divers' behavior underwater. The understanding of these areas is crucial in order to identify the risk factors. The relevant appropriate measures can then be instituted to prevent the possible environmental impact derived from divers' behavior underwater.

Similar to previous observations in Malaysia (Musa, 2002; Musa et al., 2006), scuba diving is still a predominantly male-dominated activity. The element of danger (Ewert, 1989) may have attracted slightly more male than female divers. Divers' ages are also the highest among the age group of 30s and 40s, which may reflect the better economic status among them that allows the participation in this activity. The majority of the divers $(60.9 \%)$ are Chinese, followed by $30.5 \%$ Malays. The figures are the reverse of the representation of these two groups in the Malaysian population census. This may be explained by the relatively higher economic status of Chinese, which creates greater opportunity to carry out this relatively expensive activity. Similar to the observation by Musa (2002) and Musa et al. (2006),

Table 5

Regression Analysis of Personality and Underwater Irresponsible Behavior

\begin{tabular}{|c|c|c|c|c|c|}
\hline \multirow[b]{2}{*}{ Model } & \multicolumn{2}{|c|}{$\begin{array}{l}\text { Unstandardized } \\
\text { Coefficients }\end{array}$} & \multirow{2}{*}{$\begin{array}{c}\text { Standardized } \\
\text { Coefficients: Beta }\end{array}$} & \multirow[b]{2}{*}{$t$} & \multirow[b]{2}{*}{ Sig. } \\
\hline & B & SE & & & \\
\hline (Constant) & 5.572 & 3.752 & & 1.485 & 0.139 \\
\hline P_extroversion_D1 & 0.154 & 0.217 & 0.043 & 0.707 & 0.480 \\
\hline $\mathrm{P}$ neuroticism $\mathrm{D} 2$ & 1.659 & 0.133 & 0.598 & 12.460 & 0.000 \\
\hline $\mathrm{P}_{-}^{-}$open to experience_D3 & 0.211 & 0.244 & 0.063 & 0.865 & 0.388 \\
\hline $\mathrm{P}$ agreeableness D4 & -0.894 & 0.308 & -0.220 & -2.904 & 0.004 \\
\hline $\mathrm{P}_{-}^{-}$conscientiousñess_D5 & 0.320 & 0.275 & 0.087 & 1.165 & 0.245 \\
\hline
\end{tabular}

Model 1: $R=0.618 ; R^{2}=0.383$; adjusted $R^{2}=0.372 ;$ standard estimate $=7.17357$. 
divers also have high educational achievement with $62.9 \%$ is having university education.

Generally male divers rate themselves as more experienced than female divers. Divers of other ethnicity and ethnic Chinese rate themselves as more experienced divers compared with Indian and Malay divers. This may again reflect the higher economic status among them compared with the other two ethnic groups that allow them to better participate in the activity that subsequently resulted in their greater perceived experience. The older and the more educated divers are the more likely rate themselves as experienced divers. Similar to the above arguments, these divers may have better income and opportunity to dive which subsequently contributes to their better experience. The importance of active participation in sport to increase experience has been stated earlier by Thapa et al. (2006) and Etelapelto (1998).

Divers possess the highest personality scores of agreeableness and conscientiousness. Extroversion and especially the personality score of neuroticism are low among them. Statistical analysis shows some interesting findings on the relationships between divers' demographic profile and personality. Male divers have higher personality scores of extroversion and openness to experience, while female divers score higher in neuroticism. Older divers are more likely to have the personality of extroversion, openness to experience, conscientiousness, and agreeableness. On the other hand, younger divers are more likely to have neuroticism. Higher education is related to higher openness to experience, agreeableness, and conscientiousness. Divers of Indian ethnicity score highest in neuroticism, while Chinese divers are the highest in conscientiousness.

Divers are generally responsible underwater. They are slightly more responsible with issues of safety compared with the protection of coral reef and marine life. Irresponsible behavior was higher among the younger age group. Indian divers score highest in irresponsible diving behavior, which corresponds to their higher score of neuroticism.

In aggregate form there is no significant influence of experience with underwater behavior. However, the individual experience parameters have shown some significant findings that could be used for future significant parameters in mea- suring scuba divers' experience. These are duration of involvement, total number of dives, self rating experience, and frequency of diving. The finding on the influence of the frequency of diving on the underwater behavior duplicates the observation of Davis et al. (1995). Divers who rate themselves as beginners are more irresponsible compared with the more experienced divers. All the parameters used here are important measures of experience that arrived from active involvement in activity as stated by Etelapelto (1998). The findings on the influence of experience on underwater behavior supports Thapa et al. (2006), who discovered increasing responsible behavior underwater as a result of increase in recreational specialization or experience.

Divers with higher personality score of neuroticism displayed higher irresponsible behavior underwater compared with other divers. Managers should be sensitive with divers who look unstable, anxious, worried, temperamental, and sad. These are the sign of neuroticism (Howard \& Howard, 1998). The result is expected, as Ford et al. (2001) and Fernandez and Castro (2003) noted the negative influence of anxiety and neuroticism on recreational activities.

On the other hand, the higher the personality score of agreeableness, the more likely those divers behave responsibly underwater. Thus, divers who show the characters of responsibility, good social skill, psychologically well adjusted, warmth, and enjoy interaction, as stated by Letzring (2008), are more likely to be responsible underwater. This result is especially important for the specialized dive operators who like to choose their customers for the dive trip.

This study identifies the possible high-risk group who might be more irresponsible underwater. However, the results must not be used for the purpose of discrimination or alienation. It is perhaps best used in stepping up intervention tendency of irresponsible behavior underwater. Divers who may require closer supervision are young, low in education, Indian ethnicity, and with the personality of neuroticism. For these divers perhaps the more active intervention as proposed by Barker and Roberts (2004) is indicated. For them, the simple mention of "do not touch the coral" may not be enough to prevent irresponsible 
behavior. Active intervention by a dive leader could enhance further the effort to reduce the undesirable behavior among them underwater.

Even though female divers are more likely to possess the personality dimension of neuroticism, they do not show a significant level in irresponsible behavior underwater. This contradicts the findings of Rouphael and Inglis (2001), Luna et al. (2009), and Sirakaya, 1997), all of whom stated that female divers are more responsible. It also differs from the claims of Uyarra and Cote (2007) and Worachananant et al. (2008), who stated that male divers are more responsible underwater.

The use of convenience sampling may have attracted more divers with the personality of agreeableness as these people are more likely to respond to the questionnaire. Future study may want to explore further the more extended items of irresponsible behavior underwater. It is also worth considering the use of underwater camera as one of the independent variables which influence irresponsible underwater behavior.

\section{Conclusion}

The study on the factors influencing irresponsible underwater behavior has received little attention in adventure and sport tourism literature. This study shows that divers are generally responsible underwater. The diver profiles that constitute highrisk group are the personality of neuroticism, young, low education, and Indian ethnicity. It is proposed that these divers require active intervention and close supervision underwater in order to minimize the potential likelihood of them to behave irresponsibly underwater. The scuba diving experience parameters of duration of involvement, total number of diving, self-rating experience, and frequency of diving have significant positive influences on divers' behavior underwater. These parameters could be used in the future examination scuba diving experience. Underwater, divers with high neuroticism score are more likely to behave irresponsibly, while divers with high agreeableness are likely to be more responsible. Diving operators must be aware of the symptoms of neuroticism for the purpose of closer supervision. They could also best choose divers who have higher agreeableness personality in order to minimize the potential irresponsible behavior which might cause detrimental impact to marine environment.

\section{Biographical Notes}

Ghazali Musa, a qualified medical doctor (MBBS) and a Ph.D. in tourism, is currently an Associate Professor in the Faculty of Business and Accountancy, University of Malaya, Kuala Lumpur, Malaysia. He has a wide range of interests in tourism research. Among research areas are scuba diving, health tourism, disabled tourism, tourism for elderly community, sociocultural impacts, ecotourism, high-altitude tourism, and home-stay and backpacker tourism.

Wong Tong Seng was a M.B.A. student in the Faculty of Business and Accountancy, University of Malaya, Kuala Lumpur, Malaysia.

Thinaranjeney Thirumoorthi is a Ph.D. candidate as well as a Research Assistant in the Faculty of Business and Accountancy, University of Malaya, Kuala Lumpur, Malaysia.

Massoud Abessi is an Assistant Professor from the faculty of engineering, Yazd University, Iran. He works in the areas of data mining, research methodology, MIS, simulation, design of experiments, expert systems, decision support systems, and data analysis.

\section{References}

Arney, F. M. (2004). A comparison of direct observation and self report measures of parenting behaviour. Unpublished thesis, Adelaide University.

Barker, N. H. L., \& Roberts, C. M. (2004). Scuba diver behaviour and the management of diving impacts on coral reefs. Biological Conservation, 120 (4), 481-489.

Bennet, M. (2003). Scuba diving tourism in Phuket, Thailand, pursuing sustainability. Ph.D. dissertation, University of Victoria, Canada.

Blamey, R. K. (2001). Principles of ecotourism. In D. B. Weaver (Ed.), The encyclopedia of ecotourism (pp. 522). Wallingford, UK: CAB International.

Braam, A. W., Mooi, B., Jonker, J. S., Van Tillburg, W., \& Deeg, D. J. H. (2008). God image and five factor model personality characteristics in later life: A study among inhabitants of Sassenheim in The Netherlands. Mental Health, Religion \& Culture, 11(6), 547-559.

Cater, C., \& Cater, E. (2001). Marine environments. In D. B. Weaver (Ed.), The encyclopedia of ecotourism (pp. 265-282). Wallingford, UK: CAB International.

Chapman, B. P., Lyness, J. M., \& Duberstein, P. (2007). Personality and medical illness burden among older adults in primary care. Psychosomatic Medicine, 69(3), 277-282.

Costa, Jr., P. T., \& McCrae, R. R. (1992). NEO PI-R professional manual. Odessa, FL: Psychological Assessment Resources, Inc. 
Cottrell, S. P. (2003). Influence of sociodemographics and environmental attitudes on general responsible environmental behaviour among recreational boaters. Environment and Behavior, 35(3), 347-375.

Cottrell, S. P., \& Meisel, C. (2003). Predictors of personal responsibility to protect the marine environment among divers. Proceedings of the 2003 Northeastern Recreation Research Symposium.

Davis, D. (1993). SCUBA diving: Conflicts in marine protected area. Australian Journal of Leisure and Recreation, 3(4), 65-71.

Davis, D., Harriot, V., MacNamara, C., Robert, L., \& Austin, S. (1995). Conflicts in marine protected area: Scuba divers, economics, ecology and management in Julian Rocks Aquatic Reserve. Australian Parks and Leisure, 31(1), 29-35.

Dearden, P., Bennett, M., \& Rollins, R. (2007). Perception of diving impacts and implications for reef conservation. Coastal Management, 35(2-3), 305-317.

Diamantopoulos, A., Schlegelmilch, B. B., Sinkovics, R. R., \& Bohlen, G. M. (2003). Can socio-demographics still play a role in profiling green consumers? A review of the evidence and an empirical investigation. Journal of Business Research, 56(6), 465-480.

Dignan, D. (1990). Scuba gaining among mainstream travellers. Tour and Travel News, 1, 44-45.

Dyck, C., Schneider, I., Thomas, M., \& Virden, R. (2003). Specialization among mountaineers and its relationship to environmental attitudes. Journal of Park and Recreation Administration, 21(2), 44-62.

Eccles, M. P., Hrisos, S., Francis, J., Kaner, E. F., Dickinson, H. O., Beyer, F., \& Johnston, M. (2006). Do selfreported intentions predict clinicians' behaviour: A systematic review. Implementation Science, 1(28).

Etelapelto, A. (1998). The development of expertise in information system design (Jyvasskyla studies in education, psychology and social research 146). University of Jyvasskyla.

Ewert, A. W. (1989). Outdoor adventure pursuits: Foundation, models and theories. Arizona: Publishing Horizons Inc.

Fernandez, M. L., \& Castro, Y. R. (2003). The Big Five and sexual attitude in Spanish students. Social Behavior and Personality, 31, 357-362.

Ford, N., Miller, D., \& Moss, N (2001). The role of individual differences in internet searching: An empirical study. Journal of the American Society for Information Science and Technology, 52(12), 1049-1066.

Fraj, E., \& Martinez, E. (2006). Influence of personality on ecological consumer behaviour. Journal of Consumer Behaviour, 5(3), 167-181.

Furnham, A. (1990). The development of single trait personality theories. Personality and Individual Differences, 11, 923-929.

Garrad, B., \& Wilson, J. C.(2003). Marine ecotourism: Issue and experience. Clevedon. UK: Channel View Publications.

Global Coral Reef Monitoring Network. (2000). Status of the coral reefs of the world. Townsend, Australia: Australian Institute of Marine Science.
Harriott, V., Davis, D., \& Banks, S. (1997). Recreational diving and its impact on marine protected areas in eastern Australia. Ambios, 26(3), 173-179.

Hawkins, J. P., \& Roberts, C. M. (1994). The growth of coastal tourism in the Red Sea: Present and future effects on coral reefs. Ambio, 23, 503-508.

Heinstrom, J. (2005). Fast surfing, board scanning and deep diving: The influence of personality and study approach on students' information seeking behaviour. Journal of Documentation, 61(2), 228-247.

Howard, P. J., \& Howard, J. M. (1998). An introduction to the five-factor model for personality for human resource professionals. Retrieved from www.centacs. com/quik-pt3.htm

International Coral Reef Action Network (ICRAN) Mesoamerican Reef Alliance. (2006). Standard requirements for recreational scuba diving services in the Mesoamerican Reef System. Prepared by ICRAN Mesoamerican Reef Alliance Standards and Code Taskforce. Retrieved August 10, 2008, from http://www.icran.org/pdf/CO RAL \% 20Standard\%20REquirements\%20for\%20Recre ational $\% 20$ Scuba $\% 20$ Divin $\% 20$ Services $\% 20$ in $\% 20$ the $\% 20$ MAR $\% 20-\% 20$ Standards $\% 20$ and $\% 20$ Code $\% 20$ Task \%20Force\%20May\%2006.pdf

Jensen-Campbell, L. A., Gleason, K. A., \& Adam, R. (2003). Interpersonal conflict, agreeableness and personality development. Journal of Personality, 71(6), 1059-1085.

John, O. P., \& Srivastava, S. (1999). Handbook of personality: Theory and research. In L. Pervin \& O. P. John (Eds.), The Big-Five trait taxonomy: History, measurement, and theoretical perspectives (pp. 102-138). New York: Guilford.

Kent, A. (1998). Utility of the Five-Factor Model of personality in psychotherapy aptitude-treatment interaction research. Psychotherapy Research, 8(1), 54-70.

Letzring, T. D. (2008). The good judge of personality: Characteristics, behavior and observer accuracy. Journal of Research in Personality, 42(4), pp. 914-932.

Luna, B., Valle Pérez, C., \& Sánchez-Lizaso, J. L. (2009). Benthic impacts of recreational divers in a Mediterranean Marine Protected Areas. Journal of Marine Science, 66, 517-523.

MacCarthy, M., O’Neill, M., \& Williams, P. (2006). Customer satisfaction and SCUBA diving: Some insights from the deep. The Service Industries Journal, 26(5), 537-555.

Marshall, G. N., Wortman, C. B., Vickers, R. R., Kusulas, J. W., \& Hervig, L. K. (1994). The five-factor model of personality as a framework for personality-health research. Journal of Personality and Social Psychology, $67(2), 278-286$.

Mastny, L. (2001). A world watch addendum on coral reefs. World Watch, 14(3), 20-21.

McCrae, R. R., \& John, O. (1992). An introduction to the five-factor model and its application. Journal of Personality, 60(2), 174-214.

Medio, D., Ormond, R. F. G., \& Pearson, B. (1997). Effects of briefing on rates of damage to corals by scuba divers. Biological Conservation, 79(1), 91-95. 
Marine Ecotourism for the Atlantic Area. (2001). Sample of codes of conduct for ecotourists. Retrieved August 10, 2008, from http://destinet.ew.eea.europa.eu/policies _resources/fol954381/fol924019/Codes_of_conduct_for _ecotourists.doc/

Mowen, A., Williams, D., \& Graefe, A (1997). Specialization participants and their environmental attitudes: Reexamined the role of "traditional" and psychological specialization dimensions. Proceeding of the 1996 Northeastern Recreation Research Symposium, (pp. 134-138, Gen Tech Rep. NE-232). Randor, PA: US Forest Service, Northeastern Forest Experiment Station.

Musa, G. (2002). Sipadan: A Scuba diving paradise: An analysis of tourism impact, diver satisfaction and tourism management. Tourism Geographies, 4(2), 195-209.

Musa, G., Latifah, S., Lee, L. (2006). Layang-layang: An empirical study on Scuba divers' satisfaction. Tourism in Marine Environments, 2(2), 103-109.

O'Neill, M. A., Williams, P., MacCarthy, M., \& Groves, R. (2000). Diving into service quality-the dive tour operator perspective. Managing Service Quality, 10(3), 131-140.

Phares, E. J. (1991). Introduction to psychology. (3rd ed.). New York: Harper Collins Publishers.

Ramsden, P. (1984). The context of learning. In F. Marton, D. J. Hounsell, \& N. J. Entwistle (Eds.), The experience of learning (pp. 146-64). Edinburgh: Scottish Academic Press.

Rouphael, A. B., \& Hanafy, M. (2007). An alternative management framework to limit the impact of SCUBA divers on coral assemblages. Journal of Sustainable Tourism, 15(1), 91-103.

Rouphael, A. B., \& Inglis, G. J. (2002). Increase spatial and temporal variability on coral damage caused by recreational scuba diving. Ecology Application, 12(2), 427-440.

Rouphael, A. B., \& Inglis, G. J. (2001). Take only photographs and leave only footprints? An experimental study of the impacts of underwater photographers on coral reef dive sites. Biological Conservation, 100(3), 281-287.

Sirakaya, E. (1997). Attitudinal compliance with ecotour- ism guidelines. Annals of Tourism Research, 24(4), 919-950.

Stolk, P., Markwell, K., \& Jenkins, J. M. (2007). Artificial reefs as recreational scuba diving resources: A critical review of research. Journal of Sustainable Tourism, 15(4), 331-350.

Tabata, R. S. (1992). Scuba diving holidays. In C. M. Hall, $\&$ B. Weiler, (Eds.), Special interest tourism (pp. 171184). New York, NY: Belhaven.

Thapa, B. (2000). The association of outdoor recreation activities and environmental attitudes and behaviors among forest recreationists. Unpublished doctoral dissertation, The Pennsylvania State University, University Park, PA.

Thapa, B., Graefe, A., \& Meyer, L. A. (2006). Specialization and marine based environmental behaviors among scuba divers. Journal of Leisure Research, 38(4), 601615.

Todd, S. (2000). Scuba diving in New York's great lakes: From novice to professional. SUNY: Cortland, Department of Recreation \& Leisure Studies, New York Sea Grant Institute.

Uy, F. A., Caindec, V. E. C., Perez, J. L. D., \& Dy, D. T. (2005). Impacts of recreational scuba diving on a marine protected area in Central Philippines: A case of the Gilutongan Marine Sanctuary. The Philippine Scientist, 42.

Uyarra, M. C., \& Cote, I. M. (2007). The quest for cryptic creatures: Impacts of species-focused recreational diving on corals. Biological Conservation, 136(1), 77-84.

Vermetten, Y., Lodewijks, H., \& Vermunt, J. (2001). The role of personality traits and goal orientations in strategy use. Contemporary Educational Psychology, 26(2), 149-70.

Worachananant, S., Carter, R. W., Hockings, M., \& Reopanichkul, P. (2008). Managing the impact of scuba divers on Thailand's coral reefs. Journal of Sustainable Tourism, 16(6), 645-663.

Zakai, D., \& Chadwick-Furman, N. E. (2002). Impacts of intensive recreational diving on reef corals at Eilat Northern Red Sea. Biological Conservation, 105(2), 179-187. 